\title{
In Vitro Chemosensitivity Assessed with MTT Assay in 100 Leukemic Patients
}

\author{
Zhi guo Zhang ${ }^{1}$, Jie Song ${ }^{1}$, Shuai Bai ${ }^{1}$ and Hua Yang*2 \\ ${ }^{1}$ Department of Pharmacy, the $960^{\text {th }}$ Hospital of PLA, China \\ ${ }^{2}$ Department of Immunology, Taishan Medical College, China \\ *Corresponding author: Hua Yang, Department of Immunology, Taishan Medical College, China
}

\begin{tabular}{ll}
\hline ARTICLE INFO & ABSTRACT \\
\hline
\end{tabular}

Received: 㹃 February 19, 2019

Published: 蔧 February 26, 2019

Citation: Zhi guo Zhang, Jie Song, Shuai B, Hua Y. In Vitro Chemosensitivity Assessed with MTT Assay in 100 Leukemic Patients. Biomed J Sci \& Tech Res 15(2)-2019. BJSTR. MS.ID.002665.

Keywords: Chemosensitivity; Leukemia; Drug Resistance
Chemotherapy possesses an important position in the treatment course of cancer. Cellular drug resistance is supposed to play a major role in chemotherapy failure. The purpose of this study is to investigate the feasibility of the application of MTT assay in the in vitro chemosensitivity test, in attempt to supply theory reference for clinical therapy of leukemia. We obtained peripheral blood from 100 patients with leukemia at the time of initial diagnosis or relapse. Leukemic cells were separated and the chemosensitivity testing was performed by MTT colorimetric assay. The following drugs were tested: cytarabine, vincristine, methotrexate, daunorubicin, etoposide, teniposide, homoharringtonine, doxorubicin, and mitoxantrone. The Inhibition rates of each drug for four kinds of leukemia were analyzed.

Abbreviations: DNR: Daunorubicin; VP-16: Etoposide; Ara-C: Cytosine Arabinoside; VCR: Vincristine; HHT: Homoharringtonine; MIT: Mitoxantrone; DOX: Daunomycin; VM-26: Teniposide; MTX: Methotrexate. ALL: Acute Lymphocytic Leukemia; ANLL: Acute Non Lymphocytic Leukemia; CLL: Chronic Lymphocytic Leukemia; CML: Chronic Myelogenous Leukemia

\section{Introduction}

As we all know the reason of a failure and relapse of leukemia is due to multidrug resistance. As the whole body treatment, chemotherapy possesses an important position in the treatment course of cancer. The different response is found among the individuals during the chemotherapy course, although the same tumor tissue type present. The chemotherapy for individuals has become a highlight in the research of tumor treatment and the experiment of anticancer drug sensitivity in vitro is the base and evidence for the realization of individual chemotherapy. A good way of detecting drug resistance, not taking into account the specific mechanisms of resistance, is the use of different chemosensitivity testing assays. There are many experiments for anticancer drug sensitivity at present. Among them, MTT method presents the features of simple, economic as well as accurate and is carried out by the most researchers. So we used MTT assay in the in vitro chemosensitivity test, in attempt to supply theory reference for clinical therapy of leukemia.
For the in vitro chemosensitivity testing, 100 samples with leukemic cells were separated from peripheral blood. All of these samples were technically successful and diagnosis at inclusion. Freshly obtained peripheral blood were diluted 1:1 with Hank's. Mononuclear cells were separated on Ficoll-Hypaque gradient (density: $1.077 \mathrm{~g} / \mathrm{mL}$; Solarbio, beijing, China) at 2000rpm for 20min. After washing with Hank's, the cells were resuspended in culture medium containing RPMI-1640, 10\% fetal calf serum, $100 \mathrm{IU} / \mathrm{mL}$ penicillin, and $100 \mathrm{~g} / \mathrm{mL}$ streptomycin. 9 drugs which are usually prescribed to patients were dissolved in culture medium at drug concentrations as follows: daunorubicin (DNR) $200 \mu \mathrm{g} / \mathrm{mL}$, cytosine arabinoside (Ara-C) 3000 $\mathrm{g} / \mathrm{mL}$, mitoxantron (MIT) $25 \mu \mathrm{g} /$ $\mathrm{mL}$, doxorubicin (DOX) $100 \mu \mathrm{g} / \mathrm{mL}$, etoposide (VP-16) $600 \mu \mathrm{g} / \mathrm{mL}$, vincristine (VCR) $10 \mu \mathrm{g} / \mathrm{mL}$, methotrexate (MTX) $100 \mu \mathrm{g} / \mathrm{mL}$, homoharringtonine (HHT) 10 $\mu \mathrm{g} / \mathrm{mL}$ and teniposide (VP-26) $500 \mu \mathrm{g} / \mathrm{mL}$. In this study, the concentrations of drugs in vitro were designed to mimic those in vivo situation [1]. 
$180 \mu \mathrm{L}$ cell suspension at $1 \times 106$ cells $/ \mathrm{mL}$ was incubated with $20 \mu \mathrm{L}$ each drug solution in duplicate wells of a 96-well culture plate. Control cells were cultured in the absence of test drugs. Cells were incubated at $37^{\circ} \mathrm{C}$ in a humidified $5 \% \mathrm{CO}_{2}$ atmosphere. After 2 days, $20 \mu \mathrm{L}$ of MTT (Sigma Co, St. Louis, MO, USA) in phosphate buffered salt solution $(5 \mathrm{mg} / \mathrm{mL})$ was added to each well. After $4 \mathrm{~h}$ incubation, the medium was discarded, and the formazan crystals were dissolved with $100 \mu \mathrm{L}$ of dimethyl sulfoxide (DMSO) (Sigma Co, St. Louis, MO, USA). The absorbance was measured by an automatic plate reader with a $570 \mathrm{~nm}$ test wavelength. Viability of the leukemic cells was calculated using the following equation:

\section{Inhibition rate $=1-($ OD observed/OD control) $\times 100 \%$}

The result of in vitro chemosensitivity was determined to be sensitive ( $>50 \%$ MTT dead cell) or resistant $(<50 \%$ MTT dead cell) (Figure 1) Showed the inhibition rates of a patient with chronic lymphocytic leukemia (CLL) to the 9 drugs in vitro. The patient showed resistant to MTX, VRC and Ara-C, while sensitive to other 6 drugs of the 100 patients studied in the in vitro drug sensitivity test, patients with acute lymphocytic leukemia showed sensitive to teniposide and daunorubicin, patients with acute non-lymphocytic leukemia showed sensitive to teniposide, patients with chronic lymphocytic leukemia showed sensitive to teniposide, daunorubicin, mitoxantrone, etoposide and homoharringtonine, patients with chronic myelogenous leukemia showed sensitive to teniposide and daunorubicin (Table 1). As we all known, drug resistance plays a major role in chemotherapy failures of leukemia [2,3]. MTT assay is feasible and makes it possible to selectively evaluate the effect of chemotherapy drugs in leukemic cells. In this study, we estimated the sensitivity of 9 frequently-used chemotherapeutic drugs on four types of leukemia, which may provide guidance for clinical leukemia chemotherapy. In addition, we found patients with any type of leukemia showed sensitive to teniposide, so teniposide might have a good prospect in the treatment of leukemia.

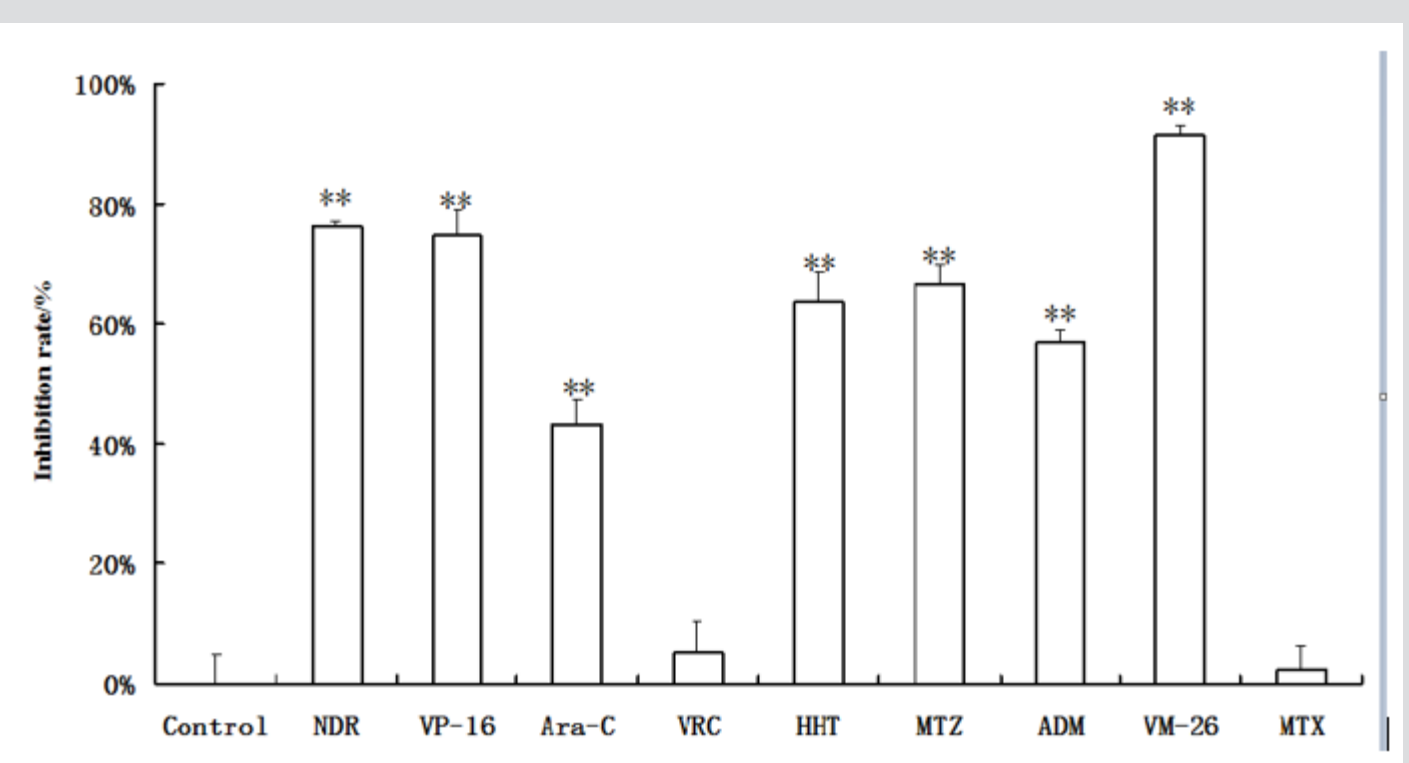

Note: Values are expressed as mean $\pm \mathrm{SD}(\mathrm{n}=4)$. Significance was determined by ANOVA followed by Dunnett's test. **P<0.01, compared to the control.

Figure 1: Effect of a patient with chronic lymphocytic leukemia (CLL) to the 9 drugs in vitro.

Table 1: Sensitivity of leukemic cells to the 9 drugs in vitro.

\begin{tabular}{|c|c|c|c|c|}
\hline \multirow{2}{*}{ Drug } & \multicolumn{4}{|c|}{ Inhibition Rate/\% } \\
\cline { 2 - 5 } & ALL $(\mathbf{n = 2 6})$ & ANNL $(\mathbf{n = 4 0})$ & CLL $(\mathbf{n = 1 3})$ & CML $(\mathbf{n = 2 1})$ \\
\hline DNR & $60.31 \pm 18.34$ & $42.37 \pm 28.76$ & $74.23 \pm 8.56$ & $60.11 \pm 13.29$ \\
\hline VP-16 & $30.47 \pm 21.9$ & $44.12 \pm 19.42$ & $64.71 \pm 12.78$ & $33.24 \pm 24.01$ \\
\hline Ara-C & $12.31 \pm 11.04$ & $18.72 \pm 11.65$ & $44.15 \pm 8.41$ & $31.56 \pm 18.29$ \\
\hline VCR & $8.97 \pm 7.43$ & $9.98 \pm 8.01$ & $17.21 \pm 11.25$ & $14.25 \pm 8.98$ \\
\hline HHT & $24.87 \pm 19.98$ & $29.71 \pm 18.01$ & $63.45 \pm 10.21$ & $34.39 \pm 14.56$ \\
\hline MIT & $34.84 \pm 17.29$ & $24.71 \pm 19.14$ & $70.97 \pm 8.94$ & $44.31 \pm 11.92$ \\
\hline DOX & $21.27 \pm 19.17$ & $14.78 \pm 10.64$ & $54.67 \pm 11.99$ & $30.13 \pm 12.92$ \\
\hline VM-26 & $84.01 \pm 8.91$ & $65.11 \pm 25.15$ & $82.82 \pm 10.44$ & $87.03 \pm 19.92$ \\
\hline MTX & $14.32 \pm 9.45$ & $9.72 \pm 8.82$ & $4.38 \pm 7.24$ & $10.07 \pm 8.42$ \\
\hline
\end{tabular}




\section{References}

1. Sundman Engberg B, Tidefelt U, Liliemark J, Paul C (1990) Intracellular concentrations of anti cancer drugs in leukemic cells in vitro vs in vivo. Cancer Chemother Pharmacol 25(4): 252-256.

2. Styczynski J, Pieters R, Huismans DR, Schuurhuis GJ, Wysocki M, et al. (2000) In vitro drug resistance profiles of adult versus childhood acute lymphoblastic leukaemia. Br J Haematol 110(4): 813-118.

ISSN: 2574-1241

DOI: 10.26717/BJSTR.2019.15.002665

Hua Yang. Biomed J Sci \& Tech Res

cC) (i) This work is licensed under Creative BY Commons Attribution 4.0 License

Submission Link: https://biomedres.us/submit-manuscript.php
3. Zwaan CM, Kaspers GJ, Pieters R, Hählen K, Janka Schaub GE, et al. (2002) Different drug sensitivity profiles of acute myeloid and lymphoblastic leukemia and normal peripheral blood mononuclear cells in children with and without Down syndrome. Blood 99(1): 245-251.

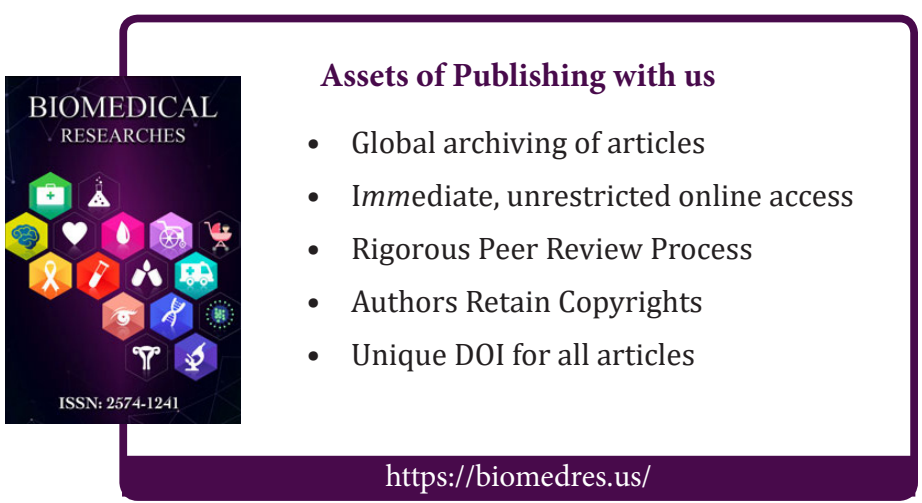

